\title{
HEREDITARY SENSORY RADICULAR NEUROPATHY
}

BY

\section{DENNY-BROWN}

\author{
From the National Hospital for Nervous Diseases, Queen Square, London, and the Department \\ of Neurology, Harvard Medical School
}

In 1922 Hicks gave a clinical description of a remarkable family of 34 members spread over four generations, 10 of whom suffered from " perforating ulcers of the feet, shooting pains about the body, and deafness". He remarked that "the condition is very nearly similar in all the patients, so that it is easy to describe a common type of the disease". He noted an onset with a painless corn in the great toe, giving way to an ulcer with indurated edges and purulent discharge after a few months. Under treatment the ulcer healed, but soon broke down again, and this intermittent healing and relapse then continued for the rest of the life of the patient. The process affected other toes, bone became exposed, and pieces of sequestrum were discharged. Finally there was considerable deformity. After an interval varying from a few months to several years shooting pains began to attack first the lower limbs, then the shoulders, head, or any part of the body. Each pain was very brief and the pains had been frequently diagnosed as lightning pains. About the time of onset of the pains the patient began to suffer from bilateral, slowly progressive deafness, leading eventually to complete loss of hearing. Hicks found that the reflexes of the lower limbs were lost, first the ankle jerks, then the knee jerks, and he had never been able to elicit.a plantar response. The reflexes in the upper limbs were retained, as also were the abdominals. The pupils always reacted to light and to accommodation. Apart from the loss of hearing there was no other evidence of impaired function of the'cranial nerves. Nystagmus was not present.

Sensation in the upper limbs was unaffected, but in the feet and legs it was severely impaired. Tactile sensation was lost over the first toe and interdigital cleft. Sensation to pain, heat, and cold was lost over a larger area extending to the rest of the foot, or even over the leg. In two cases there was very slight weakness of movements of the foot, more in a third. The Wassermann reaction of the blood was negative in two cases, and in one it was first doubtful and later negative. Death had occurred at the ages of $51,46,46$, and 49 from causes not directly related to the ulceration. Hicks gives details of 22 cases substantiating this general account.

This remarkable disease, with its marked resemblance to tabes dorsalis, has been assumed to be a great rarity, and the absence of reports of pathological examination or even of the cerebrospinal fluid in any of Hicks's cases added some possible doubt as to the nervous pathology. Hereditary and familial perforating ulcers of the feet had previously been reported by Bruns (1903), Schultze (1917), and by Göbell and Runge (1914). Bruns described a family of five siblings, the four younger members of which suffered from perforating ulcers of the feet appearing first at the age of 17 . Schultze described a family of three, a brother and two sisters, who suffered from perforating ulcers of the feet, with loss of knee and ankle jerks and of sensation in the feet. He considered lumbo-sacral syringomyelia the probable cause. Göbell and Runge (1914) had described a family in which nine members in two generations had suffered from similar ulceration. Two members were observed, and in these the knee jerks were retained, and loss of sensation was doubtful. In none of the cases described by those other authors is there mention of deafness or of shooting pains. Syringomyelia, tabes dorsalis, polyneuritis, and leprosy are discussed as possible causes. Predominant loss of sensation to pain and temperature leads all authors to incline to the first of these. Hicks considered that the condition " bears some resemblance to syringomyelia". Guillain and Thévenard (1929) have since reported two brothers suffering from perforating ulcers of the feet, with dissociated sensory loss up to the knee, but without deafness or shooting pains, under the title "familial syringomyelia". This report and others will be further discussed below.

\section{Personal Case}

Our interest in the condition was aroused by an opportunity to examine Miss R., a woman of 54 years of age, admitted to the National Hospital, 
Queen Square, London, under the care of Dr. F. M. R. Walshe in April, 1936. She was a member of the third generation of the family described by Hicks (No. 10 on his table, see Fig. 1). By 1936 many of the affected members of the first and second generations had died. Three out of six in the second generation and eight out of 22 in the third generation were affected. There are at least seven members of the fourth generation, one of whom was probably affected. The fully affected members numbered four males and six females, and transmission of the disease had occurred by both sexes (Fig. 1). The age of onset had been usually between the 22nd and 36th year of life, though one member is said to have suffered from the age of 15 years. A summary of the status of the family, at the time of our examination in 1936, containing data kindly provided by Dr. M. J. McArdle, is presented as the appendix. Denny-Brown and McArdle reported the findings in this case at a meeting of the Association of British Neurologists in 1937. The published report has been delayed in the hope that Dr. McArdle could make a clinical survey of the whole family. This, however, has not yet been possible, and my conclusions remain as they were in 1937.

The patient, Miss R., had been a seamstress, employing five or six girls, until the age of 38 when she had to give up her work on account of the trouble with her feet. For eight years she had been unable to do any needlework on account of difficulty in using her fingers.

About the age of 22 years the patient first noticed a small black area on the ball of the right great toe. There was no apparent cause. After some weeks an ulcer formed, and took about a year to heal. The next ulcer appeared when she was about 30 years of age, and ever since that time she had suffered from recurrent ulceration under the toes and the ball of the foot. The dorsum of the foot and the heel had never been affected.

Each ulcer lasted six to nine months and on occasion extended down to bone, and pieces of bone had been extruded. She had occasionally been free from ulceration for as long as a year. The ulcers occasionally ached when she rested in bed, and especially at night, but had never caused her pain in walking. An ulcer on the ball of the right foot had been there for seven months and had only recently shown signs of healing.

In her "early twenties" she began to suffer from shooting pains- " just like a knife going through"mainly in the legs and to a less extent in the arms. Each pain lasted two or three seconds, and she would get some relief by standing still and squeezing the part affected. They occurred most frequently in the thigh and shin, and had never attacked the face, neck, or trunk. In wet weather they persisted on and off the day long. In addition, she suffered from pains in her feet which seemed to be of a different nature and to last longer. These ran along the outer side of the foot from ankle to toe. She said the shin on that side was often very tender to pressure.

For about the previous 20 years she had complained of

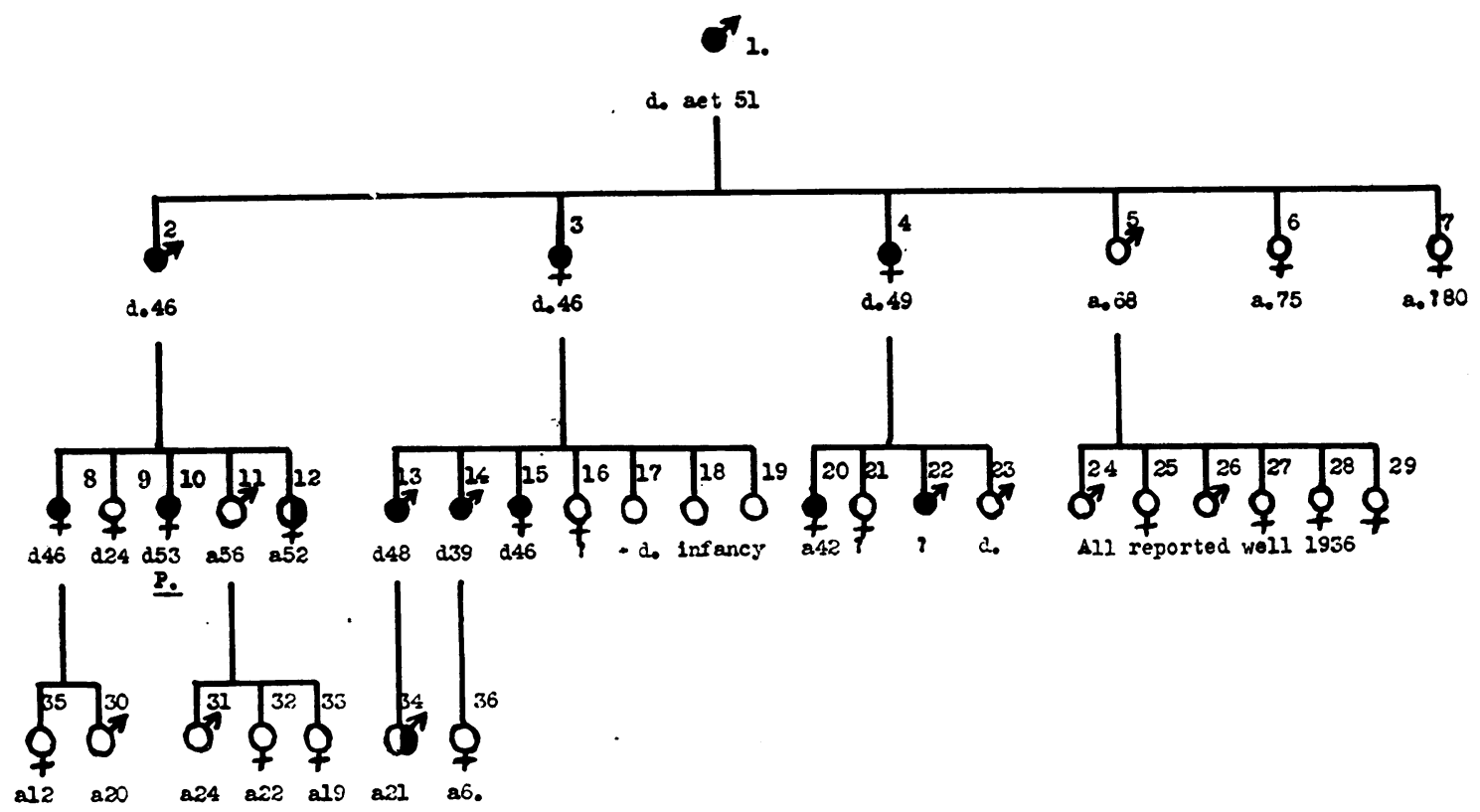

FIG. 1.-Chart of the R. family according to information available in 1936 . P. is the patient described in the text. The numbering is as in the chart of Hicks (1922) with numbers 35 and 36 added.

$\mathrm{a}=$ alive, followed by age in years in $1936 ; \mathrm{d}=$ dead, followed by age at death ; ? = fate uncertain ; $\bullet=$ affected ; $0=$ unaffected $; 0=$ tinnitus only. 
headache which was always occipital, sometimes quite high up, and at others more over the upper part of the neck. Its character varied from a continuous ache to a rapid, shooting pain. It could be "dreadful". She had had one daily in the previous few months.

Deafness began in 1921 and had steadily increased, so that by 1936 she was almost completely deaf. There had been no tinnitus. She stated that she often felt that she might fall when going downstairs and had to hold on to the bannister. For five or six years she had been unable to walk in the dark without some support. Her gait had been unsteady for three years and she tottered while walking.

Seven to eight years earlier she had had to give up needlework as she could not feel the needle distinctly with her fingers. Proper feeling was absent in the hands, and she now could not say exactly what she was holding. For quite two or three years she had had no thermal sensation in the hands and had burned herself. In the previous six months blisters had appeared on many fingers-probably the results of scalds. She burned her right leg three years earlier, and lost the right little toe through a burn, which was quite painless, two years earlier. An ulcer on the left leg was due to a burn with a hot water bottle three months before admission to hospital and showed no sign of healing.

She had had pins and needles sensations in both hands and feet in the past but not at all latterly. She thought that muscular power in the arms was normal, but diminished in the legs. There had been occasional incontinence of urine but no pain, difficulty, frequency, or nocturia. She stated that the bowels were always regular and there had been no incontinence or urgency. Her nephew later stated that she had been liable to attacks of diarrhoea for some years but not in the months preceding examination. Her sight had deteriorated and she wore glasses.

She stated that her appetite had been good and she had had no indigestion. She had often been dyspnoeic on exertion, but without pain or tightness in the chest or oedema. Her sleep was variable, depending on the amount of pain. On the whole it was good. She was accustomed to retire to bed only in the early hours of the morning, and then to spend most of the morning in bed.

Her nephew, from whom much of the history was obtained, stated that her intelligence was variable. At times she would be very dull and could not grasp what was said without much repetition. On other days she seemed "quite normal". Her memory had latterly been bad. Her temper had been equable.

This patient had been examined by Dr. Hicks in August, 1921. He wrote (1922) :

..... right big toe showed evidence of old healed
ulceration on the plantar surface; it was shorter
than the left big toe. Knee and ankle jerks absent,
supinator jerks natural, pupils reacted to light and
accommodation, no nystagmus, slight Rombergism
present. Sensation : tactile anaesthesia over first
interdigital cleft on both feet ; painful and thermal
anaesthesia over lower parts of both legs.
"Ears : slightly deaf for two years; both ears
found to be plugged with cerumen. She heard much

better after this was removed. Auditory nerve not tested on account of recent removal of cerumen."

The Wassermann reaction was not ascertained at that time.

Examination of the Central Nervous System.-The patient was a thin, poorly nourished woman of moderate height. Though thin, she was quite well preserved for her years and her hair was black without a tinge of greyness. She was not anaemic. She was severely deaf, and even with a long ear-trumpet conversation was very difficult.

She was quiet and reserved, but did not seem to be depressed. It was difficult to estimate her memory and intelligence : they appeared to be subnormal. Speech was monotonous, and high-pitched as a result of her deafness, but not otherwise abnormal.

She had occasional momentary attacks of pain in the legs and feet which made her wince and rub the affected part. They certainly suggested lightning pains. She also complained of an occipital headache.

Cranial Nerves.-The sense of smell was present in both nostrils. Vision was 6/12 R. and 6/18 L. uncorrected, the visual fields were full, the fundi and discs normal. Both pupils were smaller than usual, the right slightly smaller than the left, and both were slightly irregular. The reaction of the pupils to light and to accommodation was brisk and well held. There was no strabismus or nystagmus. Ptosis was not present. Hearing was diminished to perception of a very loud shout in either ear. Air conduction was greater than bone conduction on both sides. Weber's test showed no reference to either ear. No defect was found in the functions of the remaining cranial nerves.

Motor Function.-There was no demonstrable weakness in the muscles of the neck or trunk. Muscular development in the upper limbs was poor, and there was slight hypotonia on both sides, but no localized atrophy or weakness was detected. Coordination in the fingernose test and in alternating movement was excellent.

The posture of the lower limbs was normal, but the muscles were all thin and hypotonic. Muscular power was, however, surprisingly good, and no weakness or localized atrophy was demonstrable. There was considerable unsteadiness and irregularity of movement in heel-knee and heel-shin tests.

Reflexes.-The biceps and supinator jerks were absent in both upper limbs but the triceps jerks were both brisk. A middle abdominal reflex was obtained on both sides. There was complete absence of knee and ankle jerks. No plantar response was obtained on either side. There was full control over the sphincters.

Sensation.-The patient was a difficult witness. The sense of pain was lost over both hands and lower third of the forearms (Fig. 2). There was some impairment as high as the elbow on each side, with a fading upper border. In the lower limbs the sense of pain was completely absent below the knees and impaired to some degree as high as the groin. Pressure pain was also 

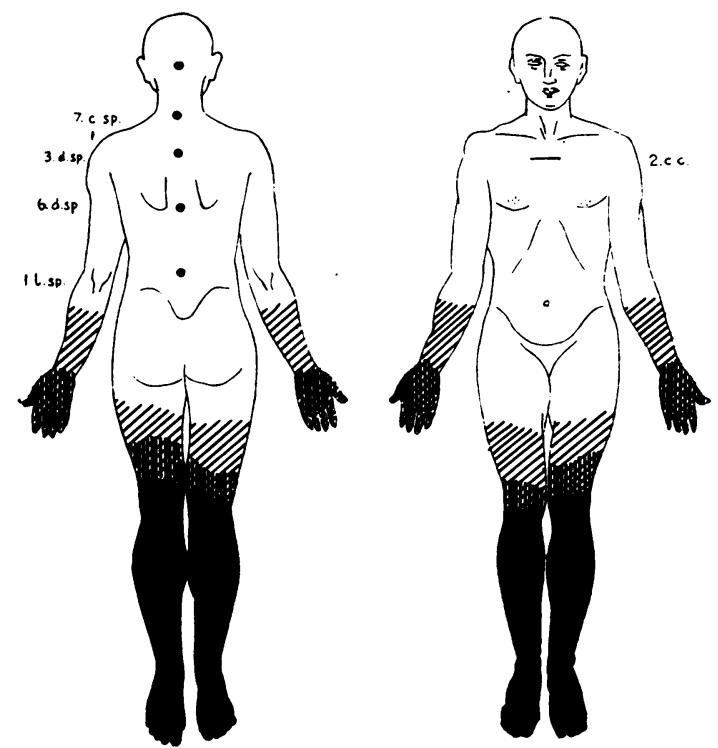

FIG. 2.-Chart of sensory loss in E.R.

The solid black area represents complete loss of all forms of sensation, the vertical shading complete loss of pain sensation, oblique shading loss of temperature sense. Impairment of temperature sensation was present in some degree over all the limbs and the trunk up to the level of the clavicles.

absent below the knee. In the proximal segments of the limbs and the lower parts of the trunk appreciation of pin prick was often delayed. The sense of touch was impaired in the fingers of both hands and absent below the knees on both legs. The sense of temperature was completely lost over the lower third of the forearm and hands, and below the middle of the thigh on both sides. The sense of vibration was diminished in the upper limbs and clavicles, and completely absent in the malleoli, knees, pelvis, and below the eleventh thoracic spine. The sense of position was present in the fingers of both hands, and absent in the toes and ankles on both sides, though the fact of movement was there appreciated. The posture of the knees was appreciated normally.

Trophic Changes.-The skin of the hands was of normal texture but there were some small corns in the flexures of the right thumb and index finger, on the pad of the second, and the side of the left index, and top of the little finger. The nails were a little brittle and pitted. When the feet were examined, it was found that the right foot was severely deformed. The right little toe was missing (burnt two years earlier) and the great toe had lost the proximal phalanx. The ball of the right foot was thickened. A small, punched-out ulcer, about $2 \mathrm{~mm}$. in diameter, was covered by scaly epithelium and lay under the head of the first metatarsal. The fourth toe on the left foot had lost the nail and terminal phalanx. The skin of the sole was greatly thickened, but there was no ulceration on that side. The remaining toe nails were cornified.

On the inner side of the left leg at its middle there was an ulcer, $50 \mathrm{~cm}$. by $30 \mathrm{~cm}$., with a sharp serpentine edge, unhealthy pink granulations, and purulent discharge. Romberg's sign was markedly positive; her gait was irregular, she staggered in walking, and had a tendency to seek support from surrounding objects.

The ulnar and peroneal nerves were palpated and did not appear thickened or tender. There was no muscular tenderness.

General Examination.-The pulse was regular and the vessels soft. Both dorsalis pedis arteries were palpable. The heart was not enlarged and the sounds were normal. No abnormality was found in the chest or abdomen. Bifid spines could be palpated from D 12 to L 2, but there was no other abnormality, and no limitation in movement. All other joints were normal. No abnormality in endocrine function was detected.

No glycosuria or albuminuria was found during the hospital admission.

Lumbar puncture revealed a clear cerebrospinal fluid under normal pressure, with normal dynamics. There were no cells seen ; the total protein was $40 \mathrm{mg}$. per 100 ml.; the Wassermann reaction was negative. The blood W.R. was negative.

Gastric analysis revealed complete achlorhydria but no other abnormality.

The blood count gave 5,100,000 R.B.Cs per c.mm.; haemoglobin, $104 \%$.

On radiological examination the loss of the phalanges seen on clinical examination was confirmed, and atrophic bony change in all the phalanges and metatarsals of both feet seen. There was no abnormality seen in radiographs of the temporal bones or spine.

Clinical Course.-The ulceration on the left leg, and the small perforating ulcer on the right foot healed completely with rest in bed for a month. The patient complained bitterly of lancinating pains in the lower limbs and in the back of the head and required regular sedation for these. She was discharged to a convalescent home and when next seen some two months later was ill with bronchopneumonia to which she succumbed.

\section{Necropsy}

Necropsy was performed by Dr. J. G. Greentield who found a thick-walled cavity about $2 \mathrm{~cm}$. in diameter at the apex of the right lung. This showed no evidence of tuberculosis in the wall, and appeared to be of pyogenic origin. Elsewhere the lungs were healthy. The gall bladder was shrunken down over a few calculi and the wall was adherent to the duodenum. In the pelvic colon there was diverticulitis with the formation of one or two small abscesses in the mesocolon. The bladder contained mucopus and the wall was intensely inflamed. Both kidneys also were very inflamed with early abscess formation in places. No evidence of amyloid degeneration was seen in sections of any organ of the body cavity.

The brain was small, weighing only $915 \mathrm{~g}$. The acoustic nerve was thin by comparison with the facial nerve and pars intermedia which appeared normal.

The spinal cord was removed along with the cervical and lumbo-sacral plexuses on the left side. The posterior roots of the cauda equina were grey and atrophic and 
the nerves were very thin, especially the sciatic and ulnar. There was no obvious deformity of the spine. The deformity of the feet was not subjected to further examination.

A series of ganglia and nerve roots, with pieces of peripheral nerve and muscle, were removed for special examination by the author. It was noted at the time that the first sacral and fifth lumbar ganglia appeared shrunken and fibrotic to the naked eye, and the attached dorsal roots particularly atrophic.

Microscopical Examination.-Transverse sections of the spinal cord and brain stem were cut at several levels. In sections of the lumbar cord stained for myelin (PalKultschitsky method) there was a considerable loss of fibres in the dorsal columns, especially in Flechsig's posterior root zone (Fig. 3). At higher levels the fasciculus gracilis was shrunken and partially demyelinated throughout but still contained many intact myelin sheaths. At the lowest cervical levels there was slight pallor at the root entry zone but the fasciculus cuneatus appeared intact in the upper cervical segments.

There was no evidence of spina bifida, syringomyelia, or dysraphism. The meninges appeared normal. In sections stained by the Nissl method the anterior horn cells in the lumbo-sacral and cervical segments were of normal appearance. There ivas no abnormal pigmentation, and no chromatolysis. The anterior roots stained well in Weigert sections, but the dorsal nerve roots had lost many fibres, especially at C 8, L 5, and S 1 levels.

Sections of the nerves and ganglia were stained by iron-haematoxylin and Van Gieson, haematoxylin-eosin, and cresyl-violet. Sample sections from these blocks were stained by the Gros-Bielchowsky method. Other blocks were mordanted and stained by Pal-Kultschitsky method. Some sections of ganglia were stained with Congo red. Frozen sections of nerve roots and ganglia were stained for fat with Scharlach $\mathbf{R}$.

The peripheral nerves and nerve roots showed a considerable loss of nerve fibres, both in sections stained for axis cylinders and those stained for myelin sheaths. The sciatic nerve had lost about one-third of its fibres at mid-thigh level. The patchy distribution of the loss was notable. The bundles of the median nerve in the forearm had a similar appearance. The posterior tibial nerve in the popliteal space had lost quite two-thirds of its fibres, and it was here clear that the remaining fibres were uniformly large (Fig. 7). Lower down, near the ankle only three or four sound fibres remained in each section of some bundles, and an estimated total of less than one-third of the nerve fibres was found in all muscular nerves. Except for an occasional fragment of axis cylinder (Fig. 4) or chain of such fragments, or myelin droplets, the remaining fibres appeared normal in structure. There was no evidence of the fine fibrils seen in regenerating nerves. Densely packed columns of Schwann cells, with mild endoneurial fibrosis were all that remained of the absent fibres. The proximal nerve trunks and plexus bundles also showed patchy loss of nerve fibres, and here and there a fibre in degeneration. There was no cellular or other infiltration, and no change in the perineuring or epineurium. The blocd vessels were normal. The appearance of the nerves was therefore that of a Wallerian degeneration of long duration with recent changes in a few isolated nerve fibres.

Section of muscle (gastrocnemius, peroneal muscles) showed normal muscle fibres and connective tissue. There was no evidence of atrophy, either of a neural or myopathic type. The blood vessels appeared normal.

Nerve Roots and Ganglia.-Sections of the nerve roots and ganglia revealed profound changes. These were most severe in the first and second sacral, and last two lumbar ganglia. There were less severe changes in the eighth cervical and first thoracic ganglia. There was great loss of ganglion cells with severe degeneration of both the peripheral and central parts of the dorsal nerve roots (Figs. 5 and 8 ). The ventral nerve roots were intact throughout (Fig. 6). In the first sacral dorsal root ganglia of both sides only 10 to 20 ganglion cells remained in each section (Fig. 9). The remaining ganglion cells, impregnated with silver, showed a great proliferation of subcapsular dendrites (Fig. 11). This change (Fig. 12) was also common in the cervical ganglia examined (C 5, C 6, D 1). In these ganglia there was some loss of ganglion cells, but milder than in the lumbo-sacral region.

In sections stained with haematoxylin-eosin the capsules and satellite cells of some of the remaining nerve cells had undergone mild proliferation. In sections impregnated with silver and counterstained with haematoxylin it was clear that such neurons had developed dense subcapsular networks. Less than $10 \%$ of the remaining ganglion cells appeared normal. In all sections only three or four cells exhibited vacuolation and nuclear shrinkage. Fat stains showed no abnormality. Pal-Kultschitsky sections confirmed the great loss of fibres and ganglion cells shown by other methods. Rarely a few droplets indicated recent degeneration of an isolated fibre. The motor nerve roots, as they passed the dorsal ganglia, showed robust normal axis cylinders and myelin (Fig. 6), with no evidence of loss of fibres.

The capsules of the dorsal root ganglia appeared normal as also were the vessels in and near the ganglia. The first sacral and lower lumbar ganglia showed a generalized increase of connective tissue. There was some proliferation of arachnoidal tissue at the point of reflection of the pia-arachnoid from nerve root to dural sheath, but no evidence of strangulation of the " radicular nerve" of Nageotte. In the ganglia the increase of perineurial fibroblastic connective tissue was diffuse, but was intense in degree only in the first sacral ganglia. where it took a pink stain with Van Gieson.

Residual nodules in the form of dense clumps of five to 15 darkly staining, spindle-shaped nuclei in an irregular star formation were common in the cervical ganglia, moderately frequent in the first dorsal ganglion, but very few remained in the sacral ganglia. In the first sacral ganglia the ganglion cells had disappeared without leaving any trace, unless they were represented by clear hyaline bodies which were scattered throughout all the sacral ganglia and were seen in small numbers in the lower lumbar and cervical ganglia. These hyaline bodies each showed some pale, elongated and distorted nuclei within them, but were not encapsulated. These bodies 


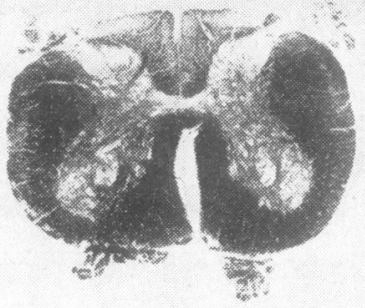

Fig. 3.-Familial perforating ulcer in Case E.R. Section of first lumbar segment of spinal cord. PalKultschitsky method for myelin.

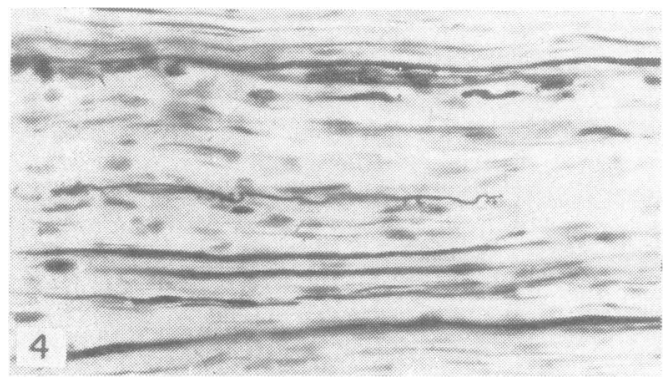

Fig. 4.-From a longitudinal section of sciatic nerve. GrosBielschowsky method for axis cylinders.

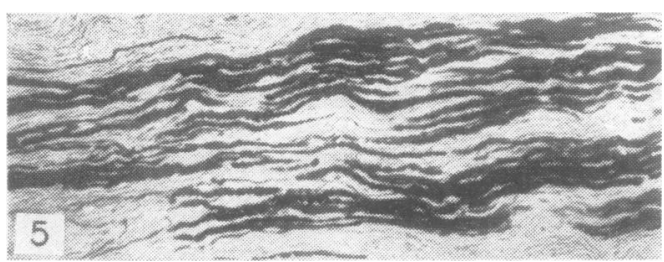

FIG. 5.-Fourth sacral dorsal root just proximal to the ganglion. Pal-Kultschitsky method for myelin.

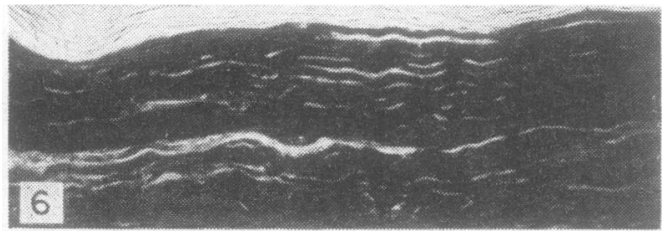

FIG. 6.-Fourth sacral ventral root just proximal to the ganglion for comparison with Fig. 5 (stained by the same method).

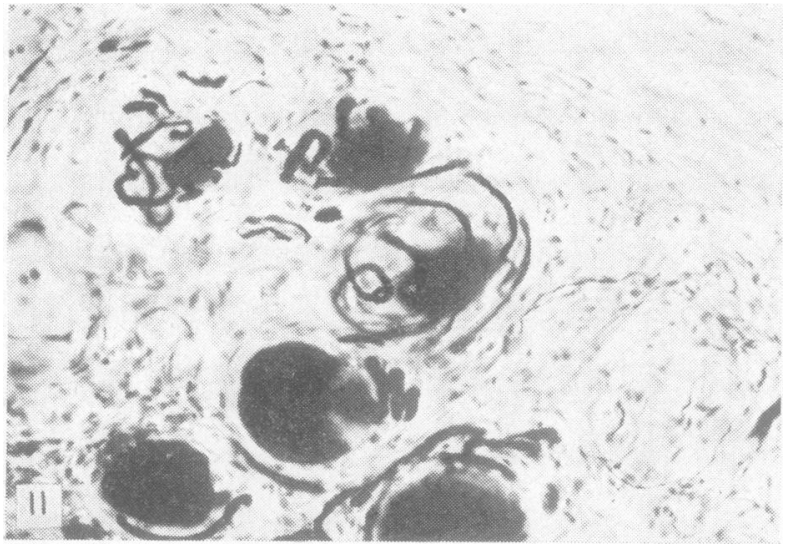

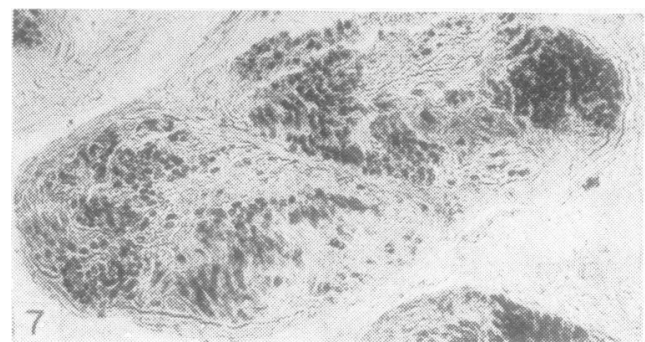

Fig. 7.-Transverse section of one fasciculus of the internal popliteal nerve in the popliteal space; same method.

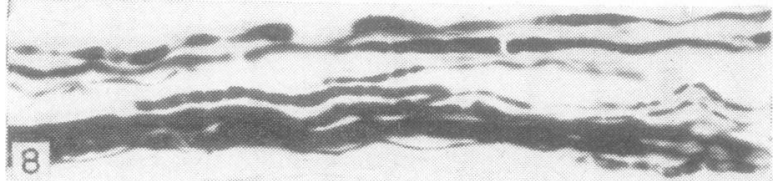

FIG. 8.-From a section of the first sacral nerve root; same method.

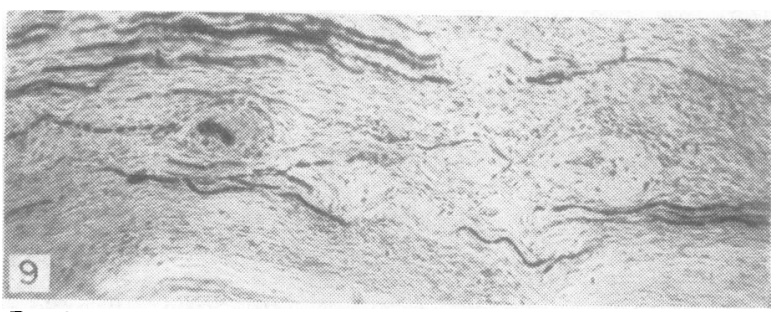

FIG. 9.-First sacral dorsal root ganglion stained by the same method. A ganglion cell is seen to the left, and a hyaline mass to the right of the centre.

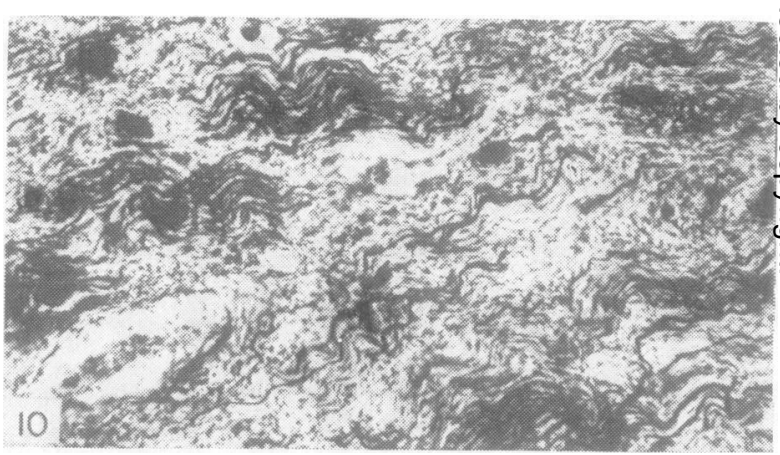

FIG. 10.-First sacral dorsal root ganglion stained by the Gros-Bielschowsky method and counterstained with haematoxylin to show residual ganglion cells, fibroblastic reaction, and two small arterioles with hyaline (amyloid) degeneration of the media.

FIG. 11.-First thoracic dorsal root ganglion stained by the Gros-Bielschowsky method and haematoxylin to show residual ganglion cells with subcapsular proliferation of dendrites. At lower right is a hyaline mass penetrated by a coiled, fine, beaded axis cylinder. 


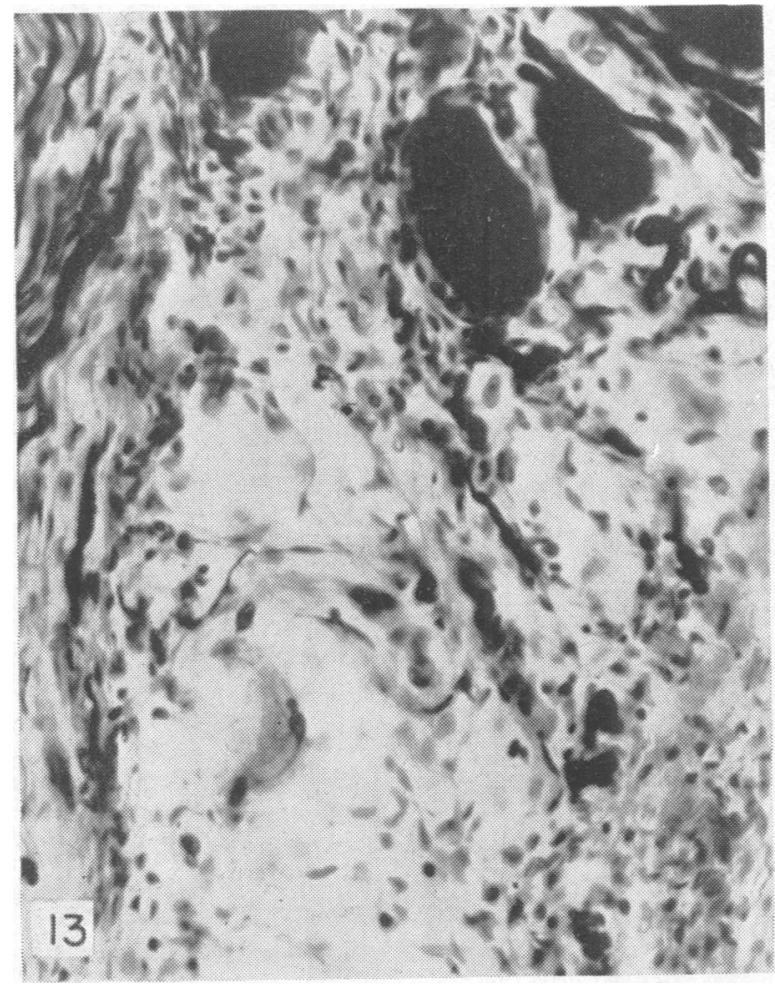

FIG. 12.-Eighth cervical dorsal root ganglion (same method) to show mild reactive changes in ganglion cells.

Fig. 13.-First thoracic dorsal root ganglion (same method) to show a large hyaline mass in the left lower part of the illustration, with convoluted capillary core and endothelium, and also a fine axis cylinder passing through it. There is an unusually intense tissue reaction surrounding this mass. The large impregnated objects are nerve cells and fibres.

FIG. 14.-As Fig. 13 to show cellular details in another mass.
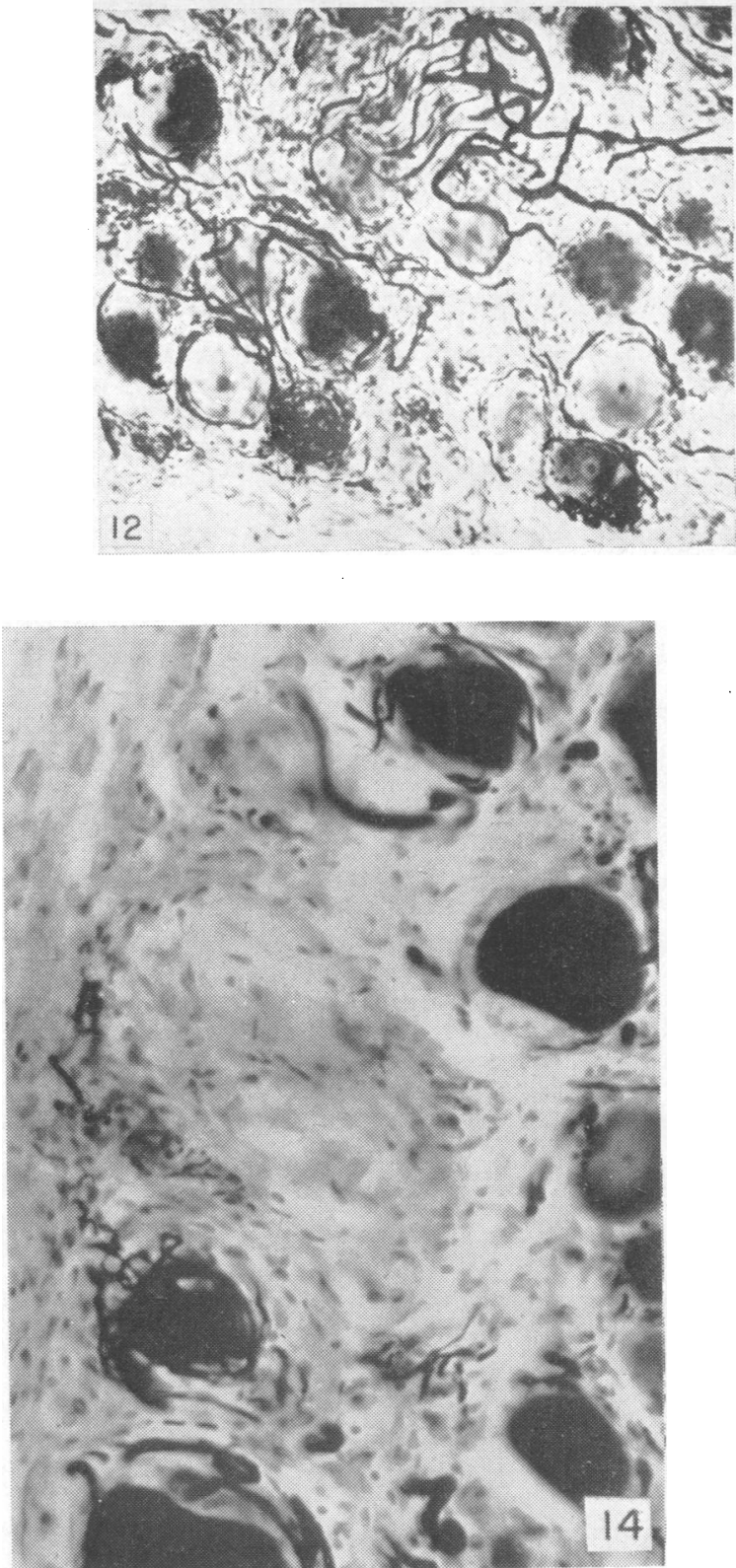

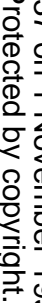

G

作 
were most numerous between the surviving ganglion cells just under the capsule of the sacral and first dorsal root ganglia (Figs. 11 and 14). The clear substance which filled them failed to stain with haematoxylin, eosin, Pal-Kultschitsky, or fat stains, and was not impregnated with silver. These bodies stained diffusely faint yellow with Van Gieson and light blue with cresyl-violet, but the latter was not attempted until some months after fixation. In formalin-fixed, celloidin-embedded material they stained from light pink to deep red with Congo red, and this dye revealed convoluted tubular cores and dark partitions in many of the masses (Fig. 15). With silver impregnation and haematoxylin it was sometimes obvious that capillary endothelium formed a central core to one or other of these masses (Fig. 13). With Congo red many of the masses had a whorled tubular central structure, strongly suggesting that the hyaline or amyloid mass had accumulated around a capillary. The ill-defined convoluted basis of such a mass as is seen in the upper left corner of Fig. 15 may represent occluded capillaries. In the centre of Fig. 15 a similar tubular structure merges into a more lightly stained mass of the material. Thus Congo red was the only dye which revealed anything of the structure of the hyaline material, which otherwise presented the appearance shown in the centre of Fig. 14. In a few instances, however, some substance which stained only with Congo red was present under the capsule of a surviving but altered ganglion cell. The arterioles and larger blood vessels of the ganglia appeared normal in every respect.

In the less severely affected cervical ganglia hyaline bodies were rarely seen, and only a hyaline thickening of some of the smaller vessels (Fig. 10) represented the change which was so conspicuous in the sacral ganglia. There were no hyaline bodies or altered capillaries in the nerve roots, peripheral nerves, spinal cord, or other tissues examined.

Silver impregnation showed that finely beaded nets of dendritic processes surrounded and penetrated some of the hyaline masses, as in Figs. 11 and 13. Many were completely devoid of nerve fibres (Fig. 14). Such nerve fibres appeared to belong to wandering branching processes of the dendritic proliferation of reacting ganglion cells.

In summary therefore, the most widely distributed changes in the dorsal root ganglia were dendritic proliferation and the presence of residual nodules, both indicating relatively recent cell damage. In the first sacral and first thoracic ganglia loss of ganglion cells was severe and residual nodules were few, and in addition many hyaline masses which gave a weak staining reaction for amyloid were present. In these ganglia there was also a moderate fibroblastic reaction. The amyloid masses appeared to have accumulated around capillary vessels, most of which were no longer patent. There was a mild tissue reaction to these masses, but no giant cells were seen. There was no such change in the vessels of the kidney, spleen, or liver, or in the ailmentary tract.

\section{Discussion}

The findings described above establish that the cause of " hereditary perforating ulcer of the foot" in the family originally reported by Hicks (1922) is a degenerative condition of dorsal root ganglia. Of 36 members of this family 11 certainly suffered from the disease in 1936. All these 11 suffered from trophic ulceration of the feet and deafness, and of these seven suffered from shooting pains closely resembling lightning pains, four from recurrent chronic diarrhoea. The upper limbs were known to be affected late in the disease in two. Two additional members suffered from tinnitus, which probably heralded the onset of further symptoms. The striking feature in all was the predominant loss of sense of pain in the feet. Though the sensory dissociation had suggested a diagnosis of syringomyelia to Hicks, and in similar cases, to Bruns. (1903), Göbell and Runge (1914), Guillain and Thévenard (1929), Wagner (1932), Smith (1934), and Mueller and Sugar (1943), that condition was not present in our case. Similarly there was no evidence of deformity of the cord or nerve roots due to spina bifida occulta, or dysraphism, as was suggested on clinical grounds by Schultze (1917), Riley (1930), and Mulvey and Riely (1942). The case of Miss R. appears to be the first reported with a pathological examination.

All these cases presented evidence of loss of pain and temperature sensation in the feet in an irregular but generally symmetrical area which in many cases. extended to the middle of the leg, and rarely as. high as the knee. Only in the cases of Göbell and Runge was loss of sensation difficult to demonstrate but it was noted that a very strong stimulus was necessary to elicit pain in the foot. If sense of touch were affected at all, it was diminished over the great toe, or a small area of the foot. Sense of vibration or position is usually not lost. The ankle jerks were absent by the time trophic disorders appeared and in many cases the knee jerks were also unobtainable. In the first case of Mulvey and Riely, however, sluggish knee and ankle jerks were obtained. Diffuse aches are commonly described, often as " rheumatism ", but lightning pains have not previously been noted. There has been usually no motor weakness or atrophy, but Bruns described weakness and slight atrophy in one case, and Riley reports others. Control of the bladder has not been affected except in one case of Bruns. The pulsation of the blood vessels in the feet, if mentioned, has been present, but many have noted coldness of the feet and in some, of the hands, long before other symptoms. The upper limbs have not been affected in other families, and deafness appears to be a feature which is unique in the R. family. The trophic disorder has been limited to the soles of the feet in all the families described, but spread of infection to involve bones of the tarsus has often necessitated amputation. 
It is therefore evident that the general clinical features of familial perforating ulcer are all capable of explanation as the result of a chronic neuritic process affecting the lumbo-sacral nerve roots. The exception to this statement is a family of three siblings reported by Verhoogen and Vandervelde (1894) in one of whom necropsy was held to demonstrate syringomyelia. These patients suffered from trophic ulceration of the hands, severe pains in the limbs and head (two cases), severe symmetrical loss of pain and temperature sense in the hands (and in two cases in the lower limbs with loss of ankle jerks, weakness and contractures), but without deafness. The one necropsy revealed a small fissure in the grey matter of the spinal cord which was interpreted as a syringomyelic cavity. Schlesinger (1902) in his monograph on syringomyelia did not accept this as evidence of that disease, which he denies may be familial. I would agree that the description of Verhoogen and Vandervelde is unconvincing, and note that the dorsal root ganglia were not examined. The dorsal columns of the spinal cord showed some degeneration, and degenerative changes in the nerves and muscles of the limbs were found. I therefore consider it probable that the pathology in the family described by Verhoogen and Vandervelde was the same that I have described. It should be emphasized however that van Bogaert (1934) has later described syringomyelia with classical distribution in the upper limb, in two sisters, in association with features of Lindau's disease. This disorder is certainly unique. It did not present as symmetrical trophic ulceration.

The entity of myelodysplasia, or dysraphism, appears to date from the conception of Fuchs (1909) who emphasized the lesser manifestations of spina bifida, with their characteristics of unvarying enuresis, syndactyly, hypertrichosis and naevi of the lumbar region. The subject has recently been fully discussed by Bremer (1937), and by Mulvey and Riely (1942), but it is evident that dissociated sensory loss sufficient to lead to trophic disorder would require a more extensive cord lesion than was postulated for myelodysplasia. The outstanding requirement of enuresis since birth, which we would consider inseparable from lumbosacral dysplasia, has been absent in familial perforating ulcer.

It is necessary to draw a sharp distinction between this slowly progressive disorder, " hereditary perforating ulcer", and the syndrome of " congenital universal indifference to pain " of which a typical case has been recently reported by Boyd and Nie (1949). Earlier cases were described by Ford and Wilkins (1938). In this condition no hypalgesia or other neurological sign is found, and though trophic disorders arise, they may be in any part of the body and are all traceable to the indifference of the patient to the presence of pain. Concomitant disturbance in the mechanism of speech in two cases suggested the possibility of a cerebral defect in recognition of pain. The disease reported here, in contrast, presented a true analgesia, primarily presenting in the cutaneous segments of the lumbosacral region.

The condition which most closely resembles hereditary perforating ulcer is the chronic symmetrical form of sensory neuritis which occurs in diabetes ("pseudotabes diabetica"). This condition, of which an excellent description is given by Pavy (1904), occurs only in extremely chronic diabetics. More extensive loss of sensation to pain and temperature than to touch, beginning commonly in the distribution of the fifth lumbar and first sacral roots, leads to trophic ulceration and arthropathy in the feet. The sphincters are involved only late in the disease. Lightning pains and ataxia are common. Deafness is not a feature. The absence of glycosuria in many examinations of at least three members of the R. family, and in many of the cases reported in the literature, makes it certain that diabetes has no part in hereditary perforating ulcer.

Sensory Dissociation.-It has been clear in all the previous cases reported that the loss of sensation to pain is greater than that to touch, and the loss to temperature greater than that to pain. The presence of this dissociation in this disease, so characteristic of damage to the grey matter of the spinal cord, demands some explanation in the absence of such damage. Two considerations suggest themselves. First, the striking loss of smaller ganglion cells and smaller nerve fibres in the most affected ganglia and nerve roots means the loss of the smaller myelinated fibres which are commonly regarded as those serving pain. Some small cells were still present, however, even in the most severely affected ganglia. Secondly, it is well known that affection of any single nerve root or sensory ganglion causes an area of sensory loss which is more extensive to temperature and pain than it is to touch. In the early stages of this disease it would appear from the clinical descriptions that it is mainly the first sacral nerve root that is affected. The corresponding sensory loss would then be of dissociated type. That this second explanation is in part valid is shown in the lesser degree of dissociation as more roots are affected, as in the case here reported (Fig. 2). If the cause of dissociation were an exclusive attack on the smaller dorsal root pain and temperature neurons, one would expect the dissociation to become more obvious as the affection progressed, whereas in the severe stage of this 
disease, all sensation was affected. It is concluded that the sensory dissociation is prominent in this disease because it is primarily a radicular affection.

Deafness.-Both temporal bones were fixed in $10 \%$ formol saline and examined histologically by Mr. Philip Scott at the Ferens Institute of the Middlesex Hospital. He reported as follows :-

"Sections show a marked reduction in the number of cells in Scarpa's ganglion. The cells of the spiral ganglion show degenerative changes and appear to be reduced in numbers, as also are some of the ciliated cells of the organ of Corti. There is some vacuolation in the stria vascularis."

This atrophy of the cochlear and vestibular ganglia parallels the atrophic process here described in the spinal ganglia. The clinical findings were of nerve deafness and in another patient in this family the findings were consistent with " primary cochlear degeneration" (Case 20, Appendix).

Weigert-Pal transverse sections of the upper medulla showed that the cochlear nerve as it entered the brain stem was fairly well myelinated but it may well have been shrunken as the sections, being longitudinal to the nerve, did not permit of any estimation of its thickness. The appearances were consistent with the number of residual cells in the spiral ganglia, which were probably still able to maintain the nutrition of their axons, and with the fairly solid, well-myelinated cochlear nerve seen in sections of the internal auditory meatus.

Unfortunately the sections of the brain stem did not go so far in a rostral direction as the entry of the vestibular divisions.

Neurogenic deafness has not been mentioned in other families reported. Deafness has, however, been reported in association with peroneal muscular atrophy by Campbell (1900), Taylor (1913), Biemond (1928), and Somogyi and Fényes (1931). It was associated with chronic hypertrophic interstitial polyneuritis in a case of Dejerine and Thomas (1901), and was found by Refsum (1946) in two of five cases of hereditary ataxic polyneuritis. It is therefore not a specific symptom, but may nevertheless represent a common factor in all these various familial and hereditary neuritides.

Pathogenesis of Perforating Ulcer.-The prominence of perforating ulcer in this family, and in the other families reported, is clearly related to the loss of pain sensation in the feet, and in some cases in the hands. In one case (Case 20, Appendix), Dr. Hicks found " slight loss to thermal sensation" but no loss to pain or touch. The demonstration of small, patchy areas of dissociated pain loss is, however, sometimes exceedingly difficult, for the patient can often distinguish between the point and head of a pin by touch alone, as in many cases of syringomyelia, without any appreciation of pain. It is concluded that trophic ulceration is dependent upon loss of pain sense and not upon the absence of any specific " trophic" nerves such as were proposed by Lancereaux (1894) and others. Indeed, the remarkable condition of " congenital universal indifference to pain" mentioned above proves clearly that trophic disorder is dependent upon absence of lack of reaction to pain and not upon any quality of pain sensation. In my case, and many others of familial perforating ulcer, the ulceration healed rapidly with rest, so that there appears no cause to doubt the widely held opinion that a perforating ulcer begins with sepsis in a corn, and assumes its characteristic deep and persistent necrosis only because the absence of pain sensation prevents the protection and adequate rest necessary for healing. Thus the perforating ulceration is regarded only as a result of loss of pain sensation in weight-bearing areas.

In the cases recorded in the $R$. family there was no evidence of neuropathic joint change. Such changes have been noted in the family reported by Bruns, and also that of Mueller and Sugar, and appeared to be precipitated by trauma to the ankle.

The pains complained of by these patients resemble lightning pains. They are presumably due to the damage to the root ganglia and have a root distribution. The condition is, however, quite distinct from tabes dorsalis, not only in the absence of pupillary abnormality, but also in the essential pathological finding that the nerve fibre degeneration occurs both distal to and proximal to the ganglion. In tabes dorsalis the degeneration is entirely proximal, as I have verified for myself in two cases. The lightning pains are to be regarded as root pains, both in tabes dorsalis and in hereditary perforating ulcer.

Relationship to Neurofibromatosis or Other Forms of Chronic Peripheral Neuritis.--The finding of large hyaline masses in the dorsal root ganglia at once called to mind the ganglionic changes reported in some cases of von Recklinghausen's disease. Two types of change occur in neurofibromatosis. One is a great thickening of the outer sheath of the dorsal root ganglion, which is continuous with the perineurium of the peripheral nerve. This is a simple fibroblastic proliferation. The other type affects the capsule of dorsal root ganglion cells, producing an onion appearance of laminated capsule cells enclosing a smaller more lightly stained whorl of proliferated satellite (Schwann) cells. Since such a ganglionic neuroma is extremely rare, an illustration is included (Fig. 16) from a 
patient suffering from generalized neurofibromatosis for comparison with the masses found in the present case. It is clearly quite different. Neither type of change was found in our case of familial

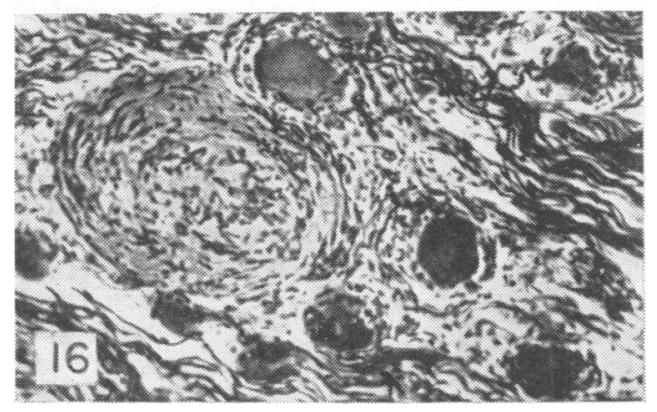

FIG. 16.-Dorsal root ganglion from a case of generalized neurofibromatosis, stained by the Gros-Bielschowsky method and haematoxylin, to show the structure of a neurofibroma of a ganglion cell, in contrast to the hyaline (amyloid) masses in the case of hereditary perforating ulcer. Note the separate proliferation of capsule and satellite cells.

perforating ulcer. The hyaline changes found in the ganglia of the case reported here were not found in our case of neurofibromatosis, or our cases of tabes dorsalis. Further, there were no changes in the nerve roots, or peripheral nerves, resembling either neurofibromatosis or the progressive interstitial hypertrophic neuritis of Dejerine and Sottas. The neural changes were of a simple degenerative kind. There was no evidence of periarteritis nodosa. A subacute degeneration of the dorsal root ganglia, associated with pulmonary carcinoma, has been reported (Denny-Brown, 1948) in two patients, in one of whom deafness occurred. The condition differed from that reported here in many respects, but indicates that the dorsal root ganglion cell may have a specific susceptibility to neuritic damage. The absence of degeneration of muscles or motor nerves in hereditary perforating ulcer serves to differentiate it completely from classical peroneal muscular atrophy. Refsum (1946) has recently described two families with ataxic polyneuritis, with some resemblance to peroneal muscular atrophy, but in addition a mixed sensory and cerebellar ataxia, and atypical retinitis pigmentosa. In three of five cases there was pupillary abnormality, and in three the protein in the cerebrospinal fluid was increased. Trophic changes were not found, though two patients had epiphysial dysplasia. My case had no resemblance to the disease reported by Refsum, which appears to be more closely allied to the syndrome of Roussy and Levy (1926). On the other hand, severe peripheral sensory disorder of radicular type has occasionally been reported in association with peroneal muscular atrophy, as in Charcot's original non-familial case Sultz of which the post-mortem examination was reported by Marinesco (1894). The changes in the dorsal nerve roots and dorsal columns of the spinal cord reported by Marinesco closely resemble those found in the present case. The case of Bruns and of Riley, discussed earlier, appear also to combine peroneal muscular atrophy with severe radicular sensory disorder. Such cases appear to be connecting links between the classical radicular type of peroneal muscular atrophy at one extreme, and the purely sensory radicular neuropathy described here. Spillane (1940) has described a family presenting many members with the RoussyLevy syndrome of familial pes cavus and areflexia, with one example of cerebellar ataxia and dysarthria resembling Friedreich's ataxia but without nystagmus, and three presenting muscular atrophy resembling peroneal muscular atrophy. Spillane therefore questioned the specificity of hereditary spinal degenerations. I prefer to classify the RoussyLevy syndrome as a separate entity with unproven, but probably spinal pathology, and to group the classical form of hereditary peroneal muscular atrophy, with or without sensory change, and the pure sensory radicular sensory syndrome presented here, as hereditary radicular degenerations which remain true to type within each family concerned.

Amyloidosis.- The accumulation of amyloid in the liver, spleen, kidneys, and heart is a well known sequel to chronic purulent disease. The absence of such accumulations in the case reported is clear evidence that such amyloid changes as were found were not related to the chronic inflammation of the feet. The nervous system appears to have an immunity to such collections of amyloid when they do occur. Rarely the blood vessels of the peripheral nerves, especially the pelvic plexus, have been reported to show collections of amyloid, and in most cases no damage to nerve fibres has resulted (Belokrenitsky, 1911 ; Königstein and Spiegel, 1924; Kernohan and Woltman, 1942). De Navasquez and Treble (1938) reported a case of chronic peripheral neuritis in a man aged 36 who had suffered from diarrhoea for two years. Amyloid deposits were found in the peripheral nerves and ganglia as well as in internal organs. Kernohan and Woltman report a further case in a man aged 50 who had had lymphadenopathy for three years, aching pains in the abdomen and extremities, and peripheral neuritis for four months. There had been one attack of diarrhoea three months before death. All tissues, including the peripheral nerves but excluding the central nervous system, showed 
extensive amyloid change. We have encountered two similar cases and also had the privilege of examining the material from De Navasquez and Treble's case. The appearance of amyloid in the peripheral nerves in such cases was very distinctive, for large irregular masses of the substance, usually with remnants of endothelial cells, lay between the nerves fibres, which were certainly as severely damaged as in our own cases. In places red blood corpuscles within an endothelial core revealed that the masses had collected around capillaries. In these cases there were also accumulations in the dorsal root ganglia, where they appeared both as isolated nodules and as cuffing to small blood vessels. One of my cases closely resembled that of Kernohan and Woltman. The other was a woman, M.L., aged 56 years, who had suffered from progressive unsteadiness and ataxia of the legs for one year, with paraesthesiae and later numbness of the feet. For five months there had been tingling, numbness, and clumsiness of the hands. In the last three months diplopia and bilateral deafness had appeared. Neither pupil reacted to light, there was ptosis and bilateral nerve deafness. There was no motor weakness or muscular atrophy, but the knee and ankle jerks were absent. There was severe loss of all forms of sensation in a glove and stocking distribution below the mid-thighs and wrists, with a fading upper border. The cerebrospinal fluid was normal in every respect (protein $40 \mathrm{mg}$. per $100 \mathrm{ml}$.). The Wassermann reaction was negative in blood and cerebrospinal fluid. The blood count was normal and a fractional test meal revealed normal free acid. There was no albuminuria. Necropsy revealed a generalized amyloidosis in every section of peripheral nerves and dorsal root ganglia. Since some of the masses of amyloid in this case closely resembled those found in my case of hereditary perforating ulcer an illustration (Fig. 17) of them is included for comparison.

It is therefore remarkable that amyloidosis can produce chronic progressive sensory neuritis and deafness. In the case of amyloid peripheral neuritis the ganglionic nodules were more numerous, more rounded and simply displaced neighbouring tissue,

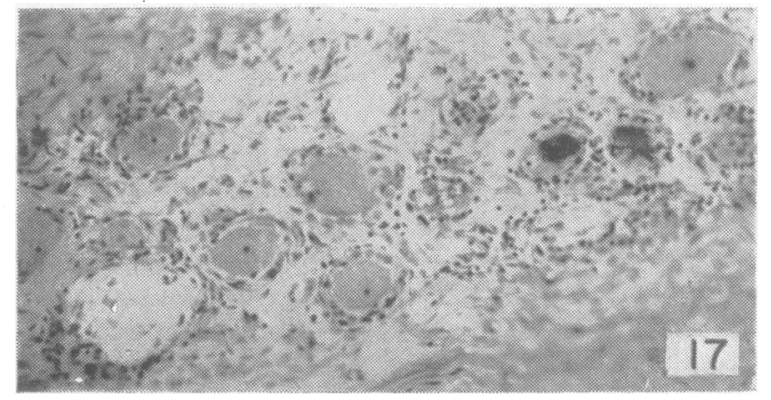

FIG. 17.-Dorsal root ganglion from case M.L. Same method. Masses of amyloid are seen at the lower left and upper centre of the figure. and there were no subcapsular collections. The general appearance was not identical with those of the ganglia of the case of hereditary perforating ulcer, but the vascular changes were the same, and some nodules had the same appearance in both diseases. These differences may, however, be only a matter of chronicity. De Navasquez and Treble reported subcapsular accumulations in their case. The case of hereditary perforating ulcer certainly had very few ganglia thus affected, and no amyloidosis of the peripheral nerves or other organs examined and thus differed greatly from the cases of amyloid neuritis I have mentioned.

The hyaline substance found in these ganglia raises precisely the same difficulty that Warren (1930) has discussed in relation to the hyaline degeneration of the islets of Langerhans in diabetes mellitus. Warren found a positive amyloid reaction in 14 of 51 cases, in the absence of generalized amyloidosis. In the latter condition the islands, like the dorsal root ganglia, are not involved as a rule. Hereditary perforating ulcer was not associated with diabetes, though it is remarkable that some chronic diabetics develop a progressive ganglionic degeneration involving the dorsal root ganglia, especially of the fifth lumbar roots, with shooting pains, and trophic ulceration of the feet. In the ganglia of two such cases which we have examined there was a generalized reactive proliferation of subcapsular dendrites, but the loss of nerve cells was not comparable to that in hereditary perforating ulcer and no hyaline or amyloid change was found.

The hyaline masses in the case of hereditary perforating ulcer showed a fainter staining reaction to cresyl-violet than do those of recent amyloid disease. They did not however present the staining reactions of mucoid, fatty, or other forms of degenerative material. Amyloid deposits in nervous tissue are evidently a capricious phenomenon, and cases of isolated amyloid deposition in the brain have been reported by several authors reviewed by Kernohan and Woltman. Until the cases of De Navasquez and Treble, and Kernohan and Woltman were reported it was not considered to be capable of causing damage to nerve fibres. The great disorganization of capillaries that is caused however must result in anoxia, which may be related to the mechanism of lightning pains in the disease under discussion. The subcapsular material present in some dorsal ganglion cells in the present case would offer more direct damage to the neuron. It is debatable whether the accumulation of amyloid is the primary feature of the disease, or is secondary to degenerative changes. I do not consider it to be the primary disorder, for many of the dorsal root cells 
show evidence of reaction to disease by proliferation of subcapsular dendrites where no such change in the capsular cells has occurred. Thickening of the walls of vessels is commonly found in relation to syringomyelic cavities in the central nervous system, for example, and Fischer and Holfelder (1930) report amyloid degeneration in the blood vessels of an area of previously irradiated brain. The amyloid bodies in my case of hereditary perforating ulcer were present only in the most severely affected ganglia, whereas ganglion cell damage and subcapsular proliferation of dendrites were widespread in nearly all the ganglia examined.

Recurrent diarrhoea is a common accompaniment of amyloidosis, and it is of interest to note that the patient here reported and also Cases 2,13 , and 8 were known to have suffered from intermittent diarrhoea. In Case 2 it occurred for two weeks as a terminal event, in Cases 8 and 13 repeatedly for years, and in Case 10 (that reported here) in bouts from 1933 to her death in 1936 . This immediately suggests the possibility of intestinal amyloidosis, but this was certainly not present.

I conclude that hereditary perforating ulcer is a primary degenerative disorder of the dorsal root ganglia, with selective incidence on those ganglia which serve the extremities. In the $R$. family secondary amyloid degeneration of blood vessels was prominent in severely affected ganglia, but this is regarded as a phenomenon secondary to some unknown metabolic defect. Though the disease has affiliations with other kinds of degeneration of the primary sensory neuron (amyloid neuritis, diabetes) it is distinct from these.

Heredity.-A glance at the genealogical table in Fig. 2 immediately reveals that the disease is transmitted as a Mendelian dominant. It has remained true to type except in two instances (Case 12 and Case 35), where tinnitus and vertigo had so far appeared as the only manifestations. One further case, and two doubtful cases are added since the record of Hicks in 1922. There is slight evidence of the "law of anticipation", for whereas the second generation first developed the disease at the ages of 31,33 , and 30 years, the third generation showed onset at the ages of $15,22,32,26,24$, and 35 years. The next generation was too young at the time of the examination in 1936 to have manifested the disease.

The families reported by others show a variety of types of inheritance, but in the larger families, such as that of Mulvey and Riely (1942) in which 11 members out of 37 in three generations were affected, the type of inheritance is clearly the same as in the ta. nily reported by Hicks and by me.

Fturther, I have seen three cases with identical clinical features but without family history. I present the sensory chart of one (Fig. 18), a young man of 24 years of age, who had attended Guy's
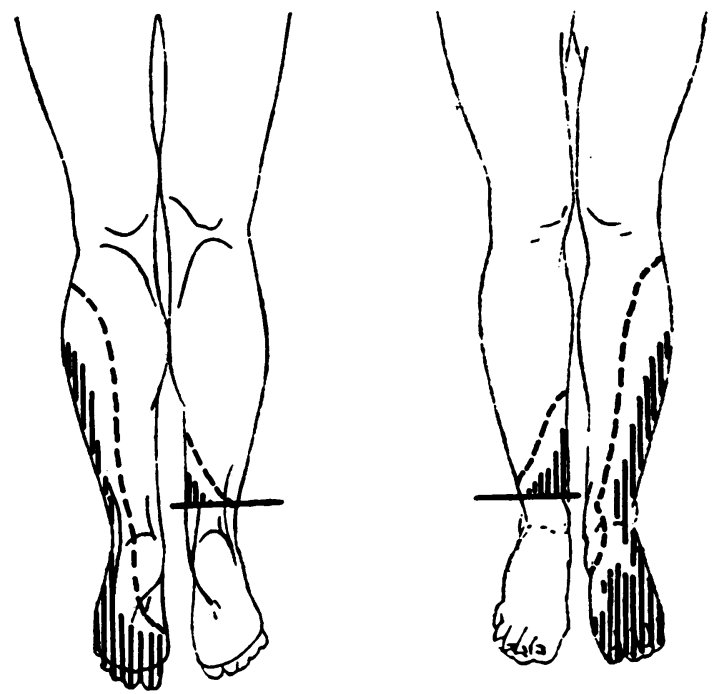

FIG. 18.-Sensory chart of G.E. aged 24. The vertical shading shows the area of loss of pain sensation. The broken line is the upper limit of hypalgesia. There was no loss of light touch sensation.

Hospital on a number of occasions since the age of about 17 years for perforating ulcer. He had had a complete neurological investigation, including serial lumbar puncture and radiographs of the spine, on several occasions, without evidence of any central pathology. The nerves were not thickened or tender, and there was no motor weakness or muscular atrophy. The ankle jerks were lost, the knee jerks present. There was no evidence of spina bifida, and no sphincter disorder. It was reported that there had been loss of sensation to pain in the right foot before it was amputated for severe trophic changes at the age of 18 . The sensory changes shown in the chart were those found when he was last seen in 1939. There was no loss of sensation to touch. The radicular distribution of the dissociated sensory loss was obvious in the left foot. Trophic ulceration of the left great toe had been recurrent for four years.

It is therefore considered that sporadic cases of symmetrical neuritic perforating ulcer are not uncommon, and that the disease we have described can have sporadic, as well as hereditary and familial forms. The absence of motor paralysis or sphincter disturbance is a frequent, but not absolute, diagnostic feature. It will be noted that smallness of the musculature and mild sphincter disorder has been seen in some cases, including our own, but only very late in the course of the disease. Sym- 
metrical bilateral paralysis of the fifth lumbar and first sacral roots, with perforating ulcers of the feet, reported by Egger and Chiray (1904), differs radically from the disease discussed here. In such cases the motor paralysis should lead to suspicion of prolapsed intervertebral disc, spinal bifida, or other cause of root lesion in spite of the absence of sphincteric paralysis. We have seen such a condition occurring as the residue of severe trauma to the cauda equina.

\section{Conclusions}

Post-mortem examination of a member of the family described by Hicks with "hereditary perforating ulcer of the foot" disclosed a primary degeneration of dorsal root ganglia. Deposits of amyloid were found in the most severely affected ganglia, and this is considered to be a secondary feature. The disease affected 11 of a family of 36 , in three generations, and was characterized by dissociated disorder of sensation beginning in the feet, with progressive deafness. Two additional members suffered from tinnitus. The disorder was inherited as a simple Mendelian dominant. The greater loss of sensations of pain and temperature is a result of the radicular pattern of sensory loss. The disease has a sporadic and familial form as well as the hereditary type, and in these deafness is absent from the syndrome.

\section{A P P E N D I X \\ HISTORY OF R. FAMILY}

No. $1^{*}$ Male

(Affected). Died 1874 at age of 51-account of relatives, ulcers in the feet, "rheumatism" (shooting pains), deafness. Arms not affected. Death certificate-" Embolism and gangrene" (Hicks).

No. 2 Male, William R.

(Affected). Brass finisher. Symptoms began in 1885 at age of 31. Repeated ulceration of both feet, amputation of second toe of right foot at age of 35, and part of left great toe at age of 44. Shooting pains in the limbs, thermal and pain loss noted in lower limbs, tendon reflexes absent, pupils reacted to light. Quite deaf in both ears for 10 years, before death in 1900 , aged 46, of "tabes mesenterica" (Hicks). Recurrent diarrhoea for last 2 years (Dr. McArdle).

No. 3 Female, Mrs. C.

(Affected). In 1897 at age of 33 began to suffer from shooting pains in the legs, and from deafness at age of 39. At age of 41 perforating ulcers on the soles of both feet. Pupils reacted to light and accommodation, knee jerks lost, anaesthesia of lower legs. Blood Wassermann negative. Died at 46 of syncope (Hicks).

No. 4 Female, Mrs. Sarah Ann B.

(Affected). Disease began at age of 30. Suffered from ulcers of the feet, pains in feet and head, and deafness. Died in 1905 at age of 49. (Statements of family-Hicks.)

No. 5 Male, Robert R., aged 68.

(Unaffected). Alive and well in 1936. No ulceration, pain, or deafness. (Statements of family.)

* Numbering according to Fig. 1.
No. 6 Female, Miss Elizabeth R.

(Unaffected). Alive and well in 1936, age 75. (Statements of family.)

No. 7 Female, Mrs. H., aged 80.

(Unaffected). Alive and well in 1936. (Statements of family.)

No. 8 Female, Mrs. Ethel C.

(Affected). Ulceration of sole of feet from age of 15. In 1919 knee jerks present, pupils reacted, no glycosuria. Blood Wassermann negative, no spinal bifida (Hicks). In 1921 wrote to Hicks stating she had now shooting pains, deafness, and more severe ulceration (Hicks). Died at age of 46-recurrent diarrhoea for the last few years. Had had amputation of foot. (Statement of relatives to Dr. McArdle.)

No. 9 Female, Lily R.

(Unaffected). Died, aged 24, of tuberculosis. Was married, no children.

No. 10 Female, Edith R.

(Affected, our patient). Died, aged 53. Onset first noticed ulceration of the feet in 1904 at the age of 22, knee and ankle jerks absent in 1921, pupils reacted to light, loss of pain and temperature sensation over lower parts of both legs, some deafness present (Hicks, August, 1921). Recurrent diarrhoea since 1933:- For terminal state see full case report.

No. 11 Male, William R.

(Unaffected). Reported alive and well, aged, 56 years, in 1936, and unaffected (information from family-Dr. McArdle).

No. 12 Female, Jane R.

(? Unaffected). Alive and well, aged 52, in 1936, suffering from chronic pulmepary 
tuberculosis. Has had intermittent tinnitus, mainly in left ear, for some months. No diarrhoea. (Seen by Dr. McArdle.)

No. 13 Male, Frank C.

(Affected). Traveller for a drug firm. Died, aged 48 years. Seen by Hicks in 1921 at age of 36 and found to have then a beginning perforating ulcer, and absence of ankle jerks. Knee jerks pressent, small patches of anaesthesia. A full report was obtained from Dr. Prausnitz of Ventnor, Isle of Wight, in 1936, stating ulceration of feet began at the age of 32 years and had been present off and on since. The knee jerks had remained present. Complete loss of sensation for pain in the feet, lower legs, and both hands. Had had bouts of diarrhoea. Very severe deafness had developed in the two years before 1936, with vertigo of Ménière type. Died in hospital in 1936; permission for necropsy refused.

No. 14 Male, Archibald C.

(Affected). Died, aged 39 years, a warehouseman, developed pulmonary tuberculosis while on active service in world war, subsequently a tram driver but gave this up in 1924 on account of ulceration in his foot. He lost the greater number of phalanges and some metatarsal bones by 1935 , with a very large ulcer present. Deafness had slowly developed from ? 1930, and was not complete. He always refused examination. The pulmonary tuberculosis appeared to have healed in 1935. Urine reported normal (no albumin) in 1935. Died of bronchopneumonia following influenza in 1937. No necropsy. (Notes from Dr. Sylvester of Newport, Isle of Wight.)

No. 15 Female

(Affected). In 1915, at the age of 24, developed ulceration of the feet, admitted to hospital in 1920 (age 29) with ulceration of feet and discharge of pieces of bone from left foot. Pupils reacted normally. Arm reflexes present. Knee jerks brisk and equal. Ankle jerks and plantar responses not obtained. Slight analgesia and confusion between heat and cold in feet only. Tactile sensation normal. Wassermann reaction in blood doubtful, December 7, 1920 , and negative, January 4, 1921. Occasional shooting pains over outer side of right thigh and in left leg at that time (account of Hicks). Patient died at age of 46 (account of relatives).

No. 16 Female

(? Unaffected). Age and whereabouts unknown.

Nos. 17, 18, 19. Died in infancy (family and Hicks). No. 20 Female, Edith B.

(Affected). First had a corn in the left foot in 1920 at the age of 35 , and intermittent pains in thighs, arms, and head, with beginning deafness, in 1921. At that time there was slight loss of thermal sensation in both feet, but none to pain or touch. Pupils reacted to light. No nystagmus. Knee jerks present but sluggish, ankle jerks, and plantar responses absent. Slight deafness present, no tinnitus. Aural surgeon reported findings analogous to primary cochlear degeneration (findings of Hicks). Reported still alive but severely affected in 1936 (information from family).

No. 21 Male

(? Unaffected). Not heard from for years.

No. 22 Male

(Affected). When last heard of in early 1920 was badly affected with ulceration of both feet, deafness, and tinnitus. No knowledge of him since (family information).

No. 23 Male

(Unaffected). Died of asthma in 1925 (information from family).

No. 24

All married and none affected in 1936 (uncertain information from family).

No. 30 Male

(Unaffected). Aged 20 in 1936, backward and slow (reliable family information).

No. 31 Male

(Unaffected). Aged 24 years in 1936. (Reliable family information.)

No. 32 ! Females. Unaffected. Aged 22 and 19 years, 33 , in 1936. (Reliable family information.)

No. 34 Male

(? Affected). Aged 21 years in 1936, radio repairer, attacks of vertigo for 3 years. No evidence of tuberculosis. No pains or paraesthesiae. Hearing normal. Pupils of moderate size and reacted briskly to light and accommodation. No wasting of muscles or weakness. No corns or ulcers. Arm jerks all sluggish. Knee jerks and ankle jerks sluggish, but all brisk with reinforcement. Plantar responses flexor. No loss of sensation to cotton wool, slight impairment to pin prick sensation below level of midcalf on both sides (examination by Dr. McArdle).

No. 35 Female, aged 12.

Unaffected in 1936 (reliable family information),

No. 36 Female, aged 6 years.

Reported healthy in 1936 (reliable family information).

\section{REFERENCES}

Belokrenitzky, S. (1911). “De la Dégénérescence Amyloïde des Nerfs." Thesis, Geneva.

Biemond, A. (1928). Dtsch. Z. Nervenheilk., 104, 113. Boyd, D. A., and Nie, L. W. (1949). Arch. Neurol. Psychiat., Chicago, 61, 402.

Bogaert, L. van (1934). Z. ges. Neurol. Psychiat., $149,661$.

Bremer, F. W. (1937). Fortschr. Neur. Psy'chiat., 9, 103. 
Bruns (1903). Neurol. Zbl., 22, 599.

Campbell, G. (1900). J. nerv. ment. Dis., 27, 274.

Dejerine, J., and Thomas, A. (1901). Rev. neurol., 9, 557.

Denny-Brown, D. (1948). Journal of Neurology, Neurosurgery and Psychiatry, 11, 73.

Egger and Chiray (1904). Rev. neurol., 12, 494.

Fischer, A. W., and Holfelder, H. (1930). Dtsch. Z. Chir., 227, 475 .

Ford, F. R., and Wilkins, L. (1938). Bull. Johns Hopk. Hosp., 62, 448.

Fuchs, A. (1909). Wien. med. Wschr., 59, 2141, 2261.

Göbell and Runge (1914). Münch. med. Wschr., 61, 102.

Guillain, G., and Thévenard, A. (1929). Ann. Méd., 25, 267.

Hicks, E. P. (1922). Lancet, 1, 319.

Kernohan, J. W., and Woltman, H. W. (1942). Arch. Neurol. Psychiat., Chicago, 47, 132.

Königstein; H., and Spiegel, E. A. (1924). Z. ges. Neurol. Psychiat., 88, 220.

Lancereaux (1894). Sem. méd., Paris, 14, 261.

Marinesco, G. (1894). Arch. Med. exp., 6, 921.

Mueller, C. R., and Sugar, S. J. (1943). J. Amer. med. Ass., 122, 743.
Mulvey, B. E., and Riely, L. A. (1942). Ann. intern. Med., 16, 966.

Navasquez, S. de, and Treble, H. A. (1938). Brain, 61, 116.

Pavy, F. W. (1904). Lancet, 2, 17, 71.

Refsum, S. (1946). Acta psychiat. Kbh., Suppl. 38.

Riley, H. A. (1930). J. nerv. ment. Dis., 72, 1.

Roussy, G., and Levy, G. (1926). Rev. neurol., 33 (I), 427.

Schlesinger, H. (1902). “Die Syringomyelie," 2nd ed. Leipzig.

Schultze, F. (1917). Dtsch. med. Wschr., 43, 545.

Smith, E. M. (1934). J. Amer. med. Ass., 102, 593.

Spillane, J. D. (1940), Brain, 63, 275.

Somogyi, I., and Fényes, I. (1931). Z. ges. Neurol. Psychiat., 137, 397.

Taylor, J. (1913). Proc. roy. Soc. Med., 6, Part 2 (Neurol. Sect.), 50.

Verhoogen, R., and Vandervelde, P. (1894). Anr. Soc. Sci. méd. nat. Brux., 3, 267.

Wagner, I. (1932). Mschr. Kinderheilk., 53, 137.

Warren, S.; (1930). "The Pathology of Diabetes Mellitus." Philadelphia. 